\title{
La verdad del mundo técnico. Ensayos para una genealogía del presente Friedrich A. Kittler
}

\author{
Alfonso Mendiola
}

\section{La verdad}

\section{del mundo técnico}

Ensayos para una genealogía del presente

Friedrich A. Kittler

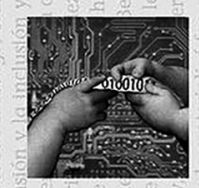

的此

Friedrich A. Kittler, La verdad del mundo técnico. Ensayos para una genealogía del presente. Ciudad de México: FCE, 2018.

\section{Preludio}

Ante las múltiples reivindicaciones actuales del realismo, pareciera que en la modernidad hay un umbral insuperable: la argumentación trascendental. La sociedad moderna sólo es capaz de reproducirse por medio de operaciones de autorreflexión. Frente a la imposibilidad que tiene ella de orientarse y tomar decisiones a partir de una realidad consistente, se ha visto obligada a elaborar teorías de la reflexión de una gran complejidad (Descartes, Kant, Hegel, Husserl, etcétera). Pero todas ellas, quizás hasta la publicación de Ser y tiempo en 1927 , han tenido como fundamento indubitable las vivencias de la conciencia, 
es decir, la verdad como certeza que se hace evidente en la privacidad "espiritual" del sujeto, ya sea egológico o intersubjetivo. La realidad moderna nunca es realidad absoluta-necesaria, sino relativa-contingente. Cada enunciado, que se refiere al mundo "real", está limitado por el punto de vista del que lo profiere. No existen prescripciones universales para emitir una ponderación. Podría afirmarse que las reglas prescriptivas siempre están condicionadas por el caso que se juzga. A cada caso sus propias reglas de juicio. Ante esta dificultad planteada por la modernidad, el único fundamento indubitable es y ha sido el "espíritu", es decir, la subjetividad. Ella, la subjetividad, en tanto que conciencia, era el refugio de lo trascendental. Este lugar de lo universal que permitiera emitir juicios objetivos, para la modernidad, se encontró en la subjetividad como "espíritu" o conciencia. Por ello, todo intento por juzgar algo, en nuestro mundo, debe partir por la explicitación de las reglas que se van a usar para realizarlo. En la modernidad, si realmente se quiere dialogar, sólo se pueden escribir prolegómenos, es decir, "críticas de la facultad de juzgar".
Esta dificultad es manifestación del surgimiento moderno de la historicidad, es decir, cada época tiene sus propios valores, pues ya no existen valores universales. Dicho de otra manera, sólo hay diálogo posible si se realiza una operación regresiva-constructiva. Regresiva porque hay que explicitar la reglas con las que la obra se produjo, para después (la acción constructiva) ver si ellas se cumplieron. Repito, en la modernidad el único género serio y responsable es el de la "crítica de la razón". Toda crítica nos explicita qué se puede decir con sentido y que no. La crítica construye límites. Ahora, si lo único que permite la modernidad es hacer críticas (esto es, si el momento regresivo es el que explicita las reglas del entendimiento), es posible que el lugar de existencia de estas reglas sea la verdad del mundo técnico y no eso que llamamos "subjetividad". Eso es lo que se pregunta Kittler. De otra manera, eso que llamamos conciencia y autoconciencia es lo que la modernidad llama hombre, conciencia, espiritu, hermenéutica, o sólo una operación que puede, únicamente, llevar a cabo el dispositivo técnico. Siempre hemos pensado que el "hombre" inventó al 
instrumento técnico y, como nos sugiere la obra de Kittler, ¿si todo fue al revés? La técnica inventó al sujeto humano, mejor dicho, ¿̨no será la técnica la que nos hace creer en la existencia de la autoconciencia?

\section{La técnica se piensa a sí misma}

Yahace un buen tiempo que he frecuentado la obra de Kittler, la cual conocí gracias a Hans Ulrich Gumbrecht. Hay que decir que no es fácil de comprender si se carece de una visión, tanto contextual como programática, de ella. Por eso trataré de presentar de manera muy esquemática esos dos puntos. Por otro lado, no puedo continuar sin destacar que el epílogo del libro, que hace Gumbrecht, es excelente. Como se puede ver en el epílogo, no sólo Gumbrecht fue un gran amigo de Kittler, sino que compartieron un mismo proyecto intelectual con sutiles diferencias. Podría decirse que este plan (freudianamente) se basa en el complejo edípico, como el propio Gumbrecht lo dice, pues consistió en matar al padre, es decir, una lucha entre dos generaciones pertenecientes a la disciplina de las humanidades, en particular a los estudios literarios, pero no sólo eso. Ahora bien, es posible caracterizar dicho proyecto de las siguientes maneras.

La primera sería la que retoma un título programático de un ensayo de Kittler que se podría traducir como la misión de "exiliar, extirpar, echar a la borda al espiritu de las ciencias del espiritu". La pregunta que surge es la siguiente: ¿qué nos queda de las humanidades -las ciencias del espíritu- si les quitamos eso que las distingue de las otras ciencias: el espíritu (la subjetividad)? Antes de profundizar en esta afirmación, podemos concluir que su objetivo -fue y ha sido- demostrar que no existen dos ciencias, las naturales y las del espíritu, sino una sola. Es decir, siguiendo a Nietzsche, "no hay alma sino sólo cuerpo". El alma, para Kittler, sólo es la manifestación de algo tan material como los mensajes eléctricos que transmite la fisiología del sistema nervioso. Por este deseo de querer extirpar el alma (el espíritu) y sólo dejar al cuerpo es que Kittler escribe su ensayo, "No hay software, sino sólo hardware".

El proyecto de Kittler tuvo su primera realización en una serie de coloquios que organizaban con el título de "materialidades de la comunicación", 
esto es, la comunicación no se basa en ideas que existen en la intimidad de la conciencia (el espíritu), sino en soportes materiales, única y solamente, tecnológicos. No hay sujeto (espíritu), sino sólo máquinas, desde la transmisión de la voz, pasando por la caligrafía, la imprenta y la máquina de escribir (la ausencia del estilo o la pluma) hasta la llegada del gramófono, el teléfono, la radio, etcétera. De esta postura surge su radical anti-humanismo. Recordemos la influencia que tuvo Michel Foucault en todo su trabajo.

Otra manera de identificar este proyecto intelectual sería con la siguiente consigna: "abandonar la hermenéutica”. Lo que buscó Kittler durante toda su trayectoria fue elaborar una teoría poshermenéutica. El espiritu de las ciencias del espiritu significa sentido. Kittler diría, siguiendo a los ingenieros de la comunicación: el sentido sólo es un dato material que se determina en una fórmula matemática. Esto nos hace recordar la máquina de inteligencia artificial del gran héroe de Kittler, Alan Turing. Dicho más claramente, la comunicación se produce, se transmite, se almacena, en soportes mate- riales que son máquinas. Aquí puede surgir la polémica de si las máquinas son una extensión de las facultades humanas, o sí entre máquina y cuerpo hay una relación inseparable. La pasión que Kittler tiene es la de eliminar la hermenéutica. Una pregunta que surge es por qué esta generación, que empieza a publicar a fines de los setenta, rechaza tan violentamente la operación de interpretación que pretende apropiarse del sentido oculto de los textos. Para él, el sentido no es algo que depende en su producción de una subjetividad, sino de los sistemas técnicos de comunicación. Para entender un mensaje hay que conocer el mecanismo del aparato técnico.

Ahora, para explicar el contexto del proyecto intelectual de Kittler es necesario recordar que su obra nace del pensamiento posestructuralista francés leído desde Heidegger. O quizás es al revés: el proyecto francés nace de una lectura novedosa de Heidegger (adelanto que esto sólo tiene la finalidad de ayudar a entender el título del libro: La verdad del mundo técnico). Kittler une de manera puntual dos obras: la de Michel Foucault y la de Martin Heidegger. Con relación al pensador 
de la Selva Negra, Kittler plantea la siguiente tesis: la aparición de la tecnología digital es el acontecimiento que permite la superación del olvido del Ser (a Kittler se le conocía como el Heidegger hippie y rockero). Como espero que se entienda al final, la tecnología digital es una vuelta, como hizo Heidegger, a los presocráticos, es decir, al momento anterior del olvido del Ser. Para el estudioso de la técnica, Kittler, el filósofo griego más importante es Pitágoras.

Los puntos que voy a exponer son: primero, datos biográficos de Kittler; en segundo, su contexto intelectual; tercero, las etapas de la evolución de su pensamiento $y$, cuarto, el significado del título del libro. Ahora, el título no sé si pudo haberlo escogido Kittler, pues el murió en 2011 y el libro se publicó en 2013. Pero sea lo que sea, el título sintetiza de manera luminosa toda su investigación. Anticipo algo que es una cita oculta o un guiño al lector: el título tiene que ver con el famoso ensayo de Martin Heidegger, La pregunta por la técnica (1949). Hay un dato que nos ayuda a entender a Kittler: su hipótesis de que la técnica se desarrolla gracias a los conflictos bélicos, fuera de aquéllos que creen en la "paz perpetua". Ese presupuesto, de que la guerra desarrolla la técnica, es la razón por la que es un gran conocedor del armamento y la estrategia de las guerras desde Napoleón hasta Hitler (y, no podemos olvidar, la Guerra Fría). Además, las guerras, evidentemente, se ganan por las armas más poderosas y destructivas, pero se ganan en lo esencial por la velocidad como se transmiten los mensajes. Pero, aún algo más, la transmisión de mensajes debe ser encriptada para que el enemigo no la entienda, más aún, como dice Kittler, todo mensaje puede ser descifrado, para entender eso sólo pensemos en la máquina de Alan Turing, Colosso, que descifró los mensajes alemanes.

Los artículos recopilados en el libro recorren toda la trayectoria de su pensamiento, la cual podemos dividir en tres etapas. Primera, la tesis de que las emociones y sentimientos sociales se forman en función de las tecnologías de la comunicación que existen en cada época. Segunda, la cultura, en su sentido amplio, se debe investigar a través de una "arqueología material de los medios de comunicación tecno- 
lógicos. $\mathrm{Y}$, por último, su interés por Grecia como el origen de la historia del Ser. Hay que destacar que Kittler se interesa por hacer una lectura materialista del Heidegger de los Aportes a la filosofía. Acerca del evento (19361938).

\section{Configuración de datos biográficos}

Digo configuración para señalar que pinto una figura a partir de algunos datos de la trayectoria vital de Kittler que nos permitan entender su obra. Esto lo resalto, pues siempre me ha parecido una falta de respeto arrojar datos, y en ocasiones muchos datos, a la cara de la gente. Además, como explica Claude Levi-Strauss en El pensamiento salvaje, a menor número de datos más explicación, a mayor número de datos menor explicación.

Kittler nace en Rochlitz el 12 de junio de 1943 y muere en Berlín el 18 de octubre de 2011. Muere, como dice su hermano en una entrevista, por causa del cigarro. Su hermano señala que empezó a fumar a los 14 años. Una de sus pasiones, que no se puede pasar por alto, pues aparece constantemente en sus ensayos, es que era un amante del rock; además, en algunas entrevistas que le hicieron, siempre resaltaba que Jim Hendrix (1942) había nacido en el mismo año que él. Otra anécdota que es relevante para entender su obra es que de joven hizo un sintetizador, pues siempre estuvo interesado en las tecnologías del sonido, desde el gramófono hasta el sonido digital.

Nace en plena Segunda Guerra Mundial y en parte del territorio de lo que será, más adelante, la Alemania Democrática. En 1956 su padre decide llevarse a toda su familia a la otra Alemania. Es muy interesante cómo cuenta ese viaje, pues es novelesco (pero lo dejaremos de lado). Se instala en Friburgo, lugar donde vivió y enseñó Heidegger. Y, estudia en la universidad de Heidegger. Resalto esto porque, como dije, toda su reflexión está marcada por él. Podríamos decir que es el pensador con el que dialogó. Hace estudios en "Historia de la literatura", tanto alemana como francesa y, junto con ellas, hace estudios de filosofía. Será profesor de manera secuencial en las siguientes universidades: Friburgo, Bochum y en la Universidad Humboldt de Berlín, hasta 
su jubilación en 2008. Es importante señalar que en Berlín es profesor de 1993 hasta 2008, pues es allí donde tendrá una cátedra sobre la tecnología, no sólo una cátedra sino también un laboratorio. Según él, sólo se entiende una máquina si se le usa. Por ello, sus discípulos han ido formado algo así como una nueva disciplina, donde confluyen muchos saberes, que se llama "Arqueología materialista de los medios".

\section{Contexto}

Su generación ve que el sistema universitario alemán es muy rígido porque, por ejemplo, el profesor deja en su puesto a su asistente. Para mirar la cultura intelectual alemana con otros ojos se dedicará a leer a los llamados posestructuralistas franceses. Kittler será un gran lector de Michel Foucault, quien influye tanto en su noción de arqueología como en su concepción de la historia. Mientras Foucault trabaja sobre la tecnología libresca, él estudiará las tecnologías que desplazaron al libro, por ello sus trabajos comprenden de fines del Xvin hasta el siglo XXI. Diré de pasada que es lector y amigo de Jacques Derrida, y un lector apasio- nado de Lacan. Podemos sostener que Kittler retorna a los autores alemanes con una mirada francesa. Por ello, su postura intelectual siempre será vista en alemania como heterodoxa.

Para no extenderme, diré que será un estudioso de la escuela de Marshall McLuhan. Y, por último, un lector de las teorías de la información elaboradas por los físicos. No se debe pasar por alto que él aprende a programar computadoras $\mathrm{y}$, por eso, enseñará programación en la universidad de Berlín.

\section{Trayectoria}

En lo fundamental, como dije antes, hay tres etapas en la trayectoria intelectual de Kittler. Cada una de ellas está marcada por sus libros más famosos. Primero la que va de la década de 1980 a 1990, que está representada por sus dos libros más conocidos: Sistemas de inscripción o registro 1800/1900 (1985), cuyo título lo toma de las Memorias de un enfermo de nervios, de Daniel Paul Schreber. Este último, en la lectura de Kittler, quiere inscribir lo que pasa en su cerebro, en el sistema nervioso, en sus Memorias; pasar de los flujos eléctricos del cerebro a la palabra inscrita en el 
papel. Una tesis de Kittler es que a fines del siglo xIX surge, por los avances de la electricidad, la psicofisiología del cerebro, pero la gente normal no siente lo que pasa en su cerebro, sólo los locos lo sienten, por ello son los únicos que pueden describir cómo funciona éste. En el siglo XIX no se podía estudiar el cerebro de un vivo, sin embargo, ahora si existe tecnología que lo puede hacer. La otra obra es Gramófono, cine, máquina de escribir (1986). La aparición de estas tres máquinas va a determinar la estructura del cuerpo humano. El gramófono logra grabar y reproducir la voz; la máquina de escribir objetiva al signo en el papel (la teoría lingüística de Saussure está basada en la máquina de escribir) y, por último, el cine permite la identificación del doble, nosotros en el espejo. Kittler relacionará estas tecnologías con los tres conceptos fundamentales de la teoría psicoanalítica de Lacan: la máquina de escribir, lo simbólico; el cine, lo imaginario y, el gramófono, lo real. La tecnología determina la estructura psíquica del hombre del siglo xx.

La segunda etapa va de 1990 a 2000 donde se dedica a estudiar la "Máquina que piensa" inventada en
1936 y materializada en 1943 por Alan Turing. Como ejemplo está el ensayo, "La inteligencia artificial de la guerra mundial: Alan Turing” (1990). Kittler siempre quiso escribir una biografía de Turing, y según su punto de vista la máquina de Turing es el fin de eso que el pensamiento moderno entendió como espíritu (subjetividad) a partir de Goethe y la filosofía alemana. La máquina de Turing viene a unir la phisis con el logos. De acuerdo con Kittler es una vuelta a los pitagóricos.

Por último, está su proyecto más ambicioso, Música y matemáticas (2009). Es un proyecto que se constituía de seis volúmenes y sólo escribió dos. Aquí sostiene que la aparición, en el siglo viII a. C. del alfabeto griego (en la época de Homero) formado de vocales va a permitir el surgimiento de la música y las matemáticas. Esto lo compara con el código binario de la máquina de Turing. Es decir, el mundo digital recupera la unidad del Ser presocrático.

\section{Significado del título}

El significado del título sintetiza toda la reflexión de Kittler, por lo que lo expondré de forma esquemática. Ki- 
ttler se concentra en el pensamiento del segundo Heidegger, el de la Kehre: el "giro", el "viraje", el "tránsito". Este Heidegger es quien abandona toda terminología relacionada con la subjetividad. Aunque ya en Ser y tiempo (1927) no habla de sujeto sino de $D a$ sein (el ser-ahí), Kittler considera que quedaron, en esa obra, aún ambigüedades que se referían a la subjetividad. Por ello, en la llamada segunda etapa de Heidegger, ya el Dasein no es el que nos permite ir al sentido del Ser, sino que es el Ser que se manifiesta en la iluminación que favorecen su aparición en la epifanía de ciertos acontecimientos (Eregnis). El "giro" de Heidegger se refiere a la parte que no escribió de Ser y tiempo, que sería Tiempo y Ser. El segundo Heidegger, siguiendo en esto la interpretación que hace Kittler de él, lo que plantea es hacer una historia del Ser (Seyn). En esta etapa de su obra ya no hablará del sentido del Ser sino de la Verdad del Ser. Aquí ya vemos cómo va emergiendo el término de verdad. Por lo tanto, la verdad de la que habla el libro no es la verdad que logra el conocimiento científico, sino la verdad en tanto que verdad del Ser que se da al estar iluminada por ciertos acontecimientos. La historia del Ser para Kittler es la historia de los medios técnicos. Para Kittler, el proyecto de Heidegger se cumple en la historia de la tecnología. Si se pone atención a la segunda parte del libro, la que se llama "La historia de la cultura como historia de los medios" se entiende porque a Kittler se le ha tachado de "determinismo tecnológico", pero lo que él sostiene es "que la tecnología configura nuestra situación", no la determina. Además, si se recuerda el primer ensayo del libro, Kittler vincula la tecnología de fines del siglo XviII con la aparición de la familia burguesa, que trae consigo el canto de la madre para arrullar al niño, más la forma de alfabetización silábica, es decir, el aprendizaje de la lectura por sílabas. Es decir, Kittler siempre articula la tecnología con las prácticas sociales.

Las reseñas, un género que nace con la publicación masiva de libros, tiene por finalidad hacer que cada libro encuentre a sus lectores, para que de esta manera empiece a existir. Espero haber ayudado a que este libro, en algunos lectores, se convierta en un instrumento que ayude a borrar el espíritu de las ciencias de espiritu. 